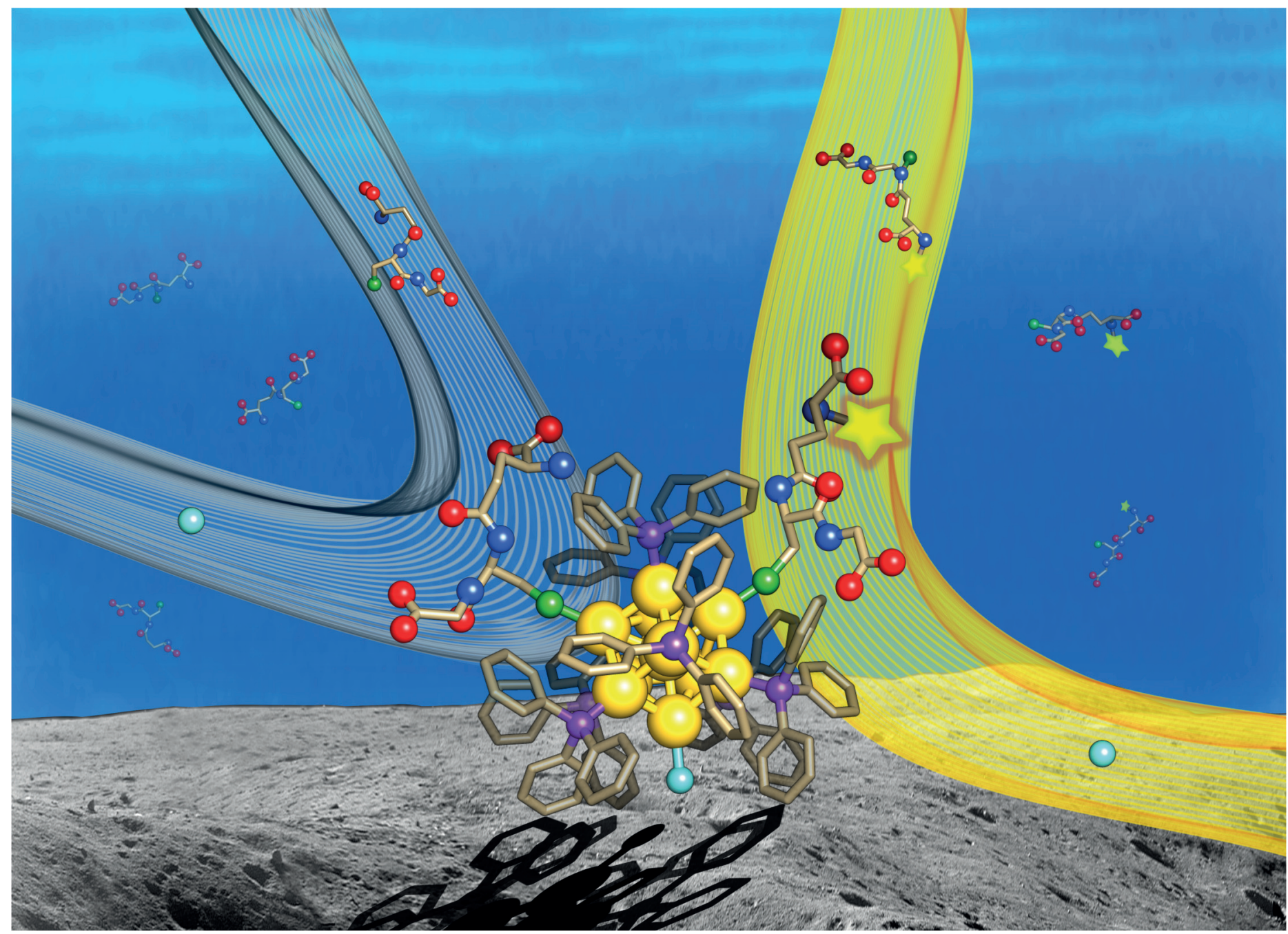

Showcasing research from ClusCAT Lab managed by Dr. Noelia Barrabés, within Prof. Günther Rupprechter's research group at the Institute of Materials Chemistry, TU Wien, Vienna, Austria.

Ligand engineering of immobilized nanoclusters on surfaces: ligand exchange reactions with supported $\mathrm{Au}_{11}\left(\mathrm{PPh}_{3}\right)_{7} \mathrm{Br}_{3}$

A $u_{11}$ nanoclusters immobilized on an alumina surface have shown to be accessible to ligand sphere transformations by thiolates in an aqueous environment. In contrast to the same ligand exchange in solution, the number of metal atoms in the core is preserved. This enables modifications of the nanocluster's structure and properties even after surface immobilization, e.g., by inducing photoluminescence through binding of fluorescent thiolates.

\section{As featured in:}

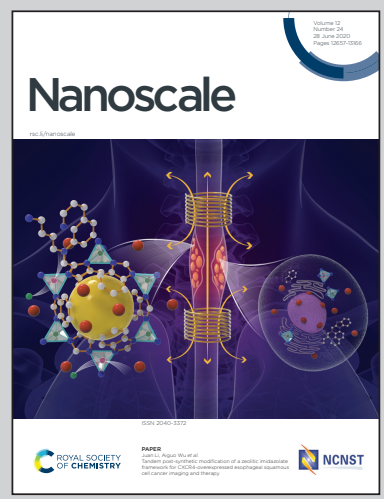

See Noelia Barrabés et al., Nanoscale, 2020, 12, 12809. 


\section{A) Check for updates}

Cite this: Nanoscale, 2020, 12, 12809

\title{
Ligand engineering of immobilized nanoclusters on surfaces: ligand exchange reactions with supported $\mathrm{Au}_{11}\left(\mathrm{PPh}_{3}\right)_{7} \mathrm{Br}_{3} \dagger$
}

\author{
Vera Truttmann, ${ }^{a}$ Christopher Herzig, (D) ${ }^{\mathrm{b}}$ Ivonne Illes, ${ }^{\mathrm{b}}$ Andreas Limbeck, (DD ${ }^{\mathrm{b}}$ \\ Ernst Pittenauer, ${ }^{b}$ Michael Stöger-Pollach, (D) ${ }^{c}$ Günter Allmaier, (D) ${ }^{b}$ \\ Thomas Bürgi, (D) d Noelia Barrabés (D) *a and Günther Rupprechter (D) ${ }^{a}$
}

The properties of gold nanoclusters, apart from being size-dependent, are strongly related to the nature of the protecting ligand. Ligand exchange on Au nanoclusters has been proven to be a powerful tool for tuning their properties, but has so far been limited to dissolved clusters in solution. By supporting the clusters previously functionalized in solution, it is uncertain that the functionality is still accessible once the cluster is on the surface. This may be overcome by introducing the desired functionality by ligand exchange after the cluster deposition on the support material. We herein report the first successful ligand exchange on supported (immobilized) $\mathrm{Au}_{11}$ nanoclusters. Dropcast films of $\mathrm{Au}_{11}\left(\mathrm{PPh}_{3}\right)_{7} \mathrm{Br}_{3}$ on planar oxide surfaces were shown to react with thiol ligands, resulting in clusters with a mixed ligand shell, with both phosphines and thiolates being present. Laser ablation inductively coupled plasma mass spectrometry and infrared spectroscopy confirmed that the exchange just takes place on the cluster dropcast. Contrary to systems in solution, the size of the clusters did not increase during ligand exchange. Different structures/compounds were formed depending on the nature of the incoming ligand. The feasibility to extend ligand engineering to supported nanoclusters is proven and it may allow controlled nanocluster

functionalization.

Received 6th December 2019 Accepted 17th March 2020

DOI: 10.1039/c9nr10353h

rsc.li/nanoscale

\section{Introduction}

Ligand protected $\mathrm{Au}$ nanoclusters, which exhibit size-selective molecular properties, are rapidly emerging nanomaterials. ${ }^{1-3}$ In general, such clusters consist of a central metal core stabilized by protecting ligands, ${ }^{2}$ such as thiolates, ${ }^{2,4,5}$ phosphines, ${ }^{6}$ selenolates, ${ }^{7-9}$ tellurolates $^{7,9}$ or alkynes. ${ }^{7}$

As the clusters' properties, including solubility, ${ }^{10,11}$ stability and optical characteristics, not only depend on the Au cluster

\footnotetext{
${ }^{a}$ Institute of Materials Chemistry, Technische Universität Wien, Getreidemarkt 9/165, 1060 Vienna, Austria. E-mail: noelia.rabanal@tuwien.ac.at

${ }^{b}$ Institute of Chemical Technologies and Analytics, Technische Universität Wien, Getreidemarkt 9/164, 1060 Vienna, Austria

${ }^{c}$ University Service Center for Transmission Electron Microscopy (USTEM), Technische Universität Wien, Wiedner Hauptstraße 8-10, 1040 Vienna, Austria ${ }^{d}$ Department of Physical Chemistry, University of Geneva, 30 Quai Ernest-Ansermet, 1211 Geneva, Switzerland

$\dagger$ Electronic supplementary information (ESI) available: Detailed description of the experimental procedures, UV-Vis and MALDI-MS spectra of the ligand exchanges in solution, additional MALDI-MS, LA-ICP-MS, PL, PM-IRRAS and ATR-IR spectra of the ligand exchange on the surface, TEM images of the clusters and the discussion of another ligand exchange on the surface with 2-PET under different conditions. See DOI: 10.1039/c9nr10353h
}

size (number of atoms), but also strongly on the nature of the protecting ligand, their modification influences the entire cluster. ${ }^{2,3,12-18}$ Ligand engineering therefore represents a strategy for producing nanoclusters with well-controlled and tunable physicochemical properties, as new functionalities such as solubility, photoluminescence, ${ }^{19,20}$ optical activity or chirality $^{21-23}$ can be selectively introduced.

Ligand exchange reactions have been widely studied in the liquid phase, pioneered almost two decades ago by investigations on thiol exchange by Murray and coworkers. ${ }^{24-28}$ Aikens's group recently gained important insights into the active sites of such exchange reactions through theoretical calculations. ${ }^{29}$ Furthermore, Hutchison and coworkers carried out intensive studies on phosphine-to-thiol exchange on $\mathrm{Au}$ nanoparticles and clusters. ${ }^{30-32}$ In 2014, they reported that in solution, $\mathrm{Au}_{11}\left(\mathrm{PPh}_{3}\right)_{7} \mathrm{Cl}_{3}$ clusters or mixtures with their analogue $\left[\mathrm{Au}_{11}\left(\mathrm{PPh}_{3}\right)_{8} \mathrm{Cl}_{2}\right] \mathrm{Cl}$, readily reacted forming $\mathrm{Au}_{25}(\mathrm{SG})_{18}$ ( $\mathrm{SG}=$ glutathionate), whereas $\left[\mathrm{Au}_{11}\left(\mathrm{PPh}_{3}\right)_{8} \mathrm{Cl}_{2}\right] \mathrm{Cl}$ clusters alone did not exchange unless harsher conditions were applied. This was attributed to differences in the stability of the two $\mathrm{Au}_{11}$ analogues. ${ }^{33}$

A strong influence of the ligand shell on the catalytic performance of gold nanoclusters has been observed: Wang et al. 
reported a significantly higher activity of $\mathrm{Au}_{11}\left(\mathrm{PPh}_{3}\right)_{7} \mathrm{Cl}_{3}$ than $\left[\mathrm{Au}_{11}\left(\mathrm{PPh}_{3}\right)_{8} \mathrm{Cl}_{2}\right] \mathrm{Cl}$ in styrene oxidation with $\mathrm{O}_{2}$, attributed to slight differences in the surrounding ligand shell. ${ }^{34}$ For 4-nitrobenzaldehyde hydrogenation, Liu et al. showed highest conversion for $\mathrm{Au}_{11}\left(\mathrm{PPh}_{2} \mathrm{Py}\right)_{7} \mathrm{Br}_{3}$ (with $\mathrm{Py}=$ pyridyl) on $\mathrm{CeO}_{2}$, when compared to $\mathrm{Au}_{11}\left(\mathrm{PPh}_{3}\right)_{7} \mathrm{Cl}_{3}$ and several thiolate protected nanoclusters. ${ }^{35}$ An effect of the nature of the ligands on the catalytic performance has also been reported for thiolate ${ }^{13,15}$ and mixed $\mathrm{PPh}_{3} /$ thiolate ${ }^{36}$ protected $\mathrm{Au}$ nanoclusters. Furthermore, comparing the performance of ligandprotected and bare clusters, phenylalkynyl stabilized $\mathrm{Au}_{34} \mathrm{Ag}_{28}$ clusters were found to be more active in organosilane oxidation than the ligand-free metal cores by Zheng and coworkers. ${ }^{37}$ Altogether, this clearly emphasizes that the controlled modification of the stabilizing ligands of cluster catalysts represents a tool for fine-tuning catalytic activity.

To improve their stability in applications such as catalysis $^{4,38,39}$ or sensing, ${ }^{40}$ the ligand-protected clusters are typically immobilized on different support materials. In the case of catalysis, the supported clusters usually undergo partial ligand removal treatments. ${ }^{4,38,41,42}$ However, other postsynthetic changes in the ligand shell, for example by the introduction of/exchange with different ligands, have not been reported so far.

With the goal to extend ligand engineering to clusters on surfaces, we performed the first study of ligand exchange reactions with supported clusters. The reaction of $\mathrm{Au}_{11}\left(\mathrm{PPh}_{3}\right)_{7} \mathrm{X}_{3}$ (with $\mathrm{X}=\mathrm{Cl}$ or $\mathrm{Br}$ ) with thiol ligands, ${ }^{30,31,33,43-45}$ a well-established ligand exchange system in solution, was chosen as a model reaction for supported clusters. Besides benefitting from the extensive knowledge of this specific reaction acquired over the last 15 years, the initial $\left(\mathrm{PPh}_{3}\right.$ and halide) and incoming (SR) ligands contain different elements ( $\mathrm{P}$ and $\mathrm{X}$ vs. $\mathrm{S}$ ), enabling straightforward discrimination. When performing ligand exchange in the liquid phase, the $\mathrm{Au}_{11}$ clusters are known to grow to $\mathrm{Au}_{25}{ }^{33,43,45}$ Depending on the exchange ligand used, the ligand shell of the exchanged cluster is then partially or fully thiolate protected: it was shown that the hydrophilic thiol ligand L-glutathione (GSH) promotes the formation of $\mathrm{Au}_{25}(\mathrm{SG})_{18},{ }^{33,43}$ whereas aliphatic thiols soluble in organic solvents usually react to give $\left[\mathrm{Au}_{25}\left(\mathrm{PPh}_{3}\right)_{10}(\mathrm{SR})_{5} \mathrm{X}_{2}\right]^{2+} \cdot{ }^{45}$

To gain first insights into the reactivity of clusters deposited on surfaces, dropcasts of $\mathrm{Au}_{11}$ on planar $\mathrm{Al}_{2} \mathrm{O}_{3}$ (oxide surface of an aluminum plate) or ZnSe surfaces were exposed to solutions of the thiol ligands. The ligand shell of the supported clusters indeed reacted, resulting in clusters containing both triphenylphosphine $\left(\mathrm{PPh}_{3}\right)$ and thiolates. However, the Au core of $\mathrm{Au}_{11}\left(\mathrm{PPh}_{3}\right)_{7} \mathrm{X}_{3}$ did not grow upon reaction, which is very different from the same ligand exchange with thiols in solution. Moreover, the extent of ligand exchange of supported clusters was found to be significantly lower than that of dissolved clusters, which may be attributed to the hindered accessibility of the supported clusters. An effect of the chemical nature of the thiol on ligand exchange reactivity was also observed, with glutathione preserving the Au core size upon reaction, whereas 2-phenylethanethiol facilitated the dissolution of the clusters.

\section{Experimental}

\section{Synthetic procedures}

Synthesis of $\mathbf{A u}_{11}\left(\mathbf{P P h}_{3}\right)_{7} \mathbf{B r}_{3}$. The starting clusters $\mathrm{Au}_{11}\left(\mathrm{PPh}_{3}\right)_{7} \mathrm{Br}_{3}$ were synthesized following a procedure slightly modified from that described in the literature ${ }^{33,35,46,47}$ (see the $\mathrm{ESI} \dagger$ for details). Briefly, the gold precursor $\mathrm{HAuCl}_{4} \cdot 3 \mathrm{H}_{2} \mathrm{O}$ was dissolved in tetrahydrofuran (THF) with the aid of tetraoctylammonium bromide (TOAB). After the addition of $\mathrm{PPh}_{3}$, the reaction mixture was reduced with $\mathrm{NaBH}_{4}$ over 48 hours. After some washing steps, the desired cluster species was obtained by extraction with dichloromethane (DCM) and characterized with nuclear magnetic resonance spectroscopy (NMR), matrixassisted laser desorption/ionization mass spectrometry (MALDI-MS) and ultraviolet-visible spectroscopy (UV-Vis; see the ESI $\dagger$ ).

Synthesis of fluorescein labeled L-glutathione. The fluorescent ligand was prepared following a published protocol. ${ }^{48}$ Oxidized glutathione was reacted with fluorescein isothiocyanate to yield a mixture of fluorescein labeled disulfides, which were separated by solid phase extraction. The desired reduced fluorescein labeled L-glutathione (F-GSH) was then obtained by reacting it with tris(2-carboxyethyl)phosphine, followed by another solid phase extraction step. Refer to the ESI $\uparrow$ for further details.

Ligand exchange in solution. The ligand exchange reactions of the dissolved $\mathrm{Au}_{11}\left(\mathrm{PPh}_{3}\right)_{7} \mathrm{Br}_{3}$ with L-glutathione (GSH) and 2-phenylethanethiol (2-PET) were carried out as described elsewhere. ${ }^{8,30-33,43-45}$ The $\mathrm{Au}_{25}$ clusters obtained after 24 hours of reaction time - $\mathrm{Au}_{25}(\mathrm{SG})_{18}$ for $\mathrm{GSH}$ as the exchange ligand and $\left[\mathrm{Au}_{25}\left(\mathrm{PPh}_{3}\right)_{10}(2 \text {-PET })_{5} \mathrm{Br}_{2}\right]^{2+}$ for 2-PET - were analyzed with UV-vis spectroscopy and MALDI-MS. Spectra can be found in the ESI (Fig. S2-S5†). The results were in perfect agreement with the literature, confirming the purity and reactivity of the synthesized $\mathrm{Au}_{11}\left(\mathrm{PPh}_{3}\right)_{7} \mathrm{Br}_{3}$.

Ligand exchange with supported clusters. For ligand exchange with supported clusters, the $\mathrm{Au}_{11}$ precursor was dropcasted onto a planar $\mathrm{Al}_{2} \mathrm{O}_{3}$ surface (top layer of an aluminum plate). The samples were then exposed to solutions of the two thiols glutathione (GSH) or 2-phenylethanethiol (2-PET) at room temperature and the reactions were followed with polarization-modulation infrared reflection-absorption spectroscopy (PM-IRRAS). The exchange products $\left[\mathrm{Au}_{11}: \mathrm{GSH}\right]$ (for $\mathrm{GSH}$ ) and $\left[\mathrm{Au}_{11}: 2\right.$-PET $]$ (for 2-PET) were further analyzed: the presence of sulfur in the reacted samples was confirmed with laser ablation inductively coupled plasma mass spectrometry (LA-ICP-MS); transmission electron microscopy (TEM), highangle annular dark-field scanning transmission electron microscopy (HAADF-STEM) and MALDI-MS were performed to investigate possible changes in cluster size. For ligand exchange with GSH, a corresponding ligand exchange experiment with $\mathrm{Au}_{11}\left(\mathrm{PPh}_{3}\right)_{7} \mathrm{Br}_{3}$ supported on a $\mathrm{ZnSe}$ crystal was per- 
formed and monitored in situ with attenuated total reflection infrared (ATR-IR) spectroscopy. Ligand exchange on supported $\mathrm{Au}_{11}$ with fluorescein-labeled glutathione (F-GSH) was conducted following the same procedure as for the exchange with unlabeled GSH.

\section{Characterization}

UV-Vis, PL, IR (PM-IRRAS, ATR-IR) and NMR spectroscopy, as well as mass spectrometry (LA-ICP-MS, MALDI-MS) and electron microscopy (TEM, HAADF-STEM) measurements were employed to study the pure and supported cluster samples. Refer to the ESI $\uparrow$ for details.

\section{Results and discussion}

As a starting point, the synthesized $\mathrm{Au}_{11}\left(\mathrm{PPh}_{3}\right)_{7} \mathrm{Br}_{3}$ was reacted with the thiol ligands L-glutathione (GSH) and 2-phenylethanethiol (2-PET) in solution, to confirm that the undecagold clusters showed the same reactivity as reported previously $^{30,31,33,43,45}$ (see the ESI $\dagger$ ). Indeed, we obtained $\mathrm{Au}_{25}(\mathrm{SG})_{18}$ for $\mathrm{GSH}$ as the exchange ligand and $\left[\mathrm{Au}_{25}\left(\mathrm{PPh}_{3}\right)_{10}(2-\mathrm{PET})_{5} \mathrm{Br}_{2}\right]^{2+}$ for 2-PET as the exchange ligand, confirming core growth from $\mathrm{Au}_{11}$ to $\mathrm{Au}_{25}$ upon reaction (Scheme 1). For ligand exchange with supported (immobilized) clusters, experiments were subsequently carried out with $\mathrm{Au}_{11}\left(\mathrm{PPh}_{3}\right)_{7} \mathrm{Br}_{3}$ dropcast films on alumina plates, which were exposed to solutions of the same thiol ligands, leading to products referred to as $\left[\mathrm{Au}_{11}: \mathrm{GSH}\right]$ and $\left[\mathrm{Au}_{11}: 2-\mathrm{PET}\right]$ as follows (Scheme 1).
Polarization-modulation infrared reflection-absorption spectroscopy (PM-IRRAS) was applied to monitor the reactions. Due to the modulation, the signal of background gas phase molecules is removed and the surface sensitivity is thus high, making it an ideal method for analyzing the reacted samples. ${ }^{49}$ The aluminum plate supporting the clusters was taken out of the ligand solution in regular intervals, washed and fully dried before recording PM-IRRAS spectra. In the examined wavenumber region, only vibrations of the organic ligands contribute to the spectrum and changes in the clusters' ligand shell should thus cause pronounced changes in the PM-IRRAS spectral features.

Indeed, when following the reaction of a dropcast film of $\mathrm{Au}_{11}\left(\mathrm{PPh}_{3}\right)_{7} \mathrm{Br}_{3}$ with $\mathrm{GSH}$ to $\left[\mathrm{Au}_{11}: \mathrm{GSH}\right]$, drastic changes were observed (Fig. 1a). The bands showed significant broadening, in addition to new spectral features, which can be assigned to the characteristic vibrations of GSH. Besides the $\mathrm{C}=\mathrm{O}$ vibration at $\approx 1720 \mathrm{~cm}^{-1}$, bands were also appearing in the amide I \& II regions (1500-1700 $\left.\mathrm{cm}^{-1}\right) \cdot{ }^{50,51}$ Referenced to the spectrum of a pure GSH dropcast on alumina (Fig. 1a), the profile exhibits a very similar shape, though appearing slightly red-shifted compared to the free ligand due to bonding to the $\mathrm{Au}$ clusters. In addition, the most intense bands of the original $\mathrm{PPh}_{3}$ ligand were still visible in the final spectrum after the reaction (1436, 1097 and $1025 \mathrm{~cm}^{-1}$ ). This clearly indicates a partial exchange of the ligands, with both $\mathrm{PPh}_{3}$ and GSH being present in the product. In contrast, for the ligand exchange of $\mathrm{Au}_{11}\left(\mathrm{PPh}_{3}\right)_{7} \mathrm{Br}_{3}$ with 2-PET to [ $\mathrm{Au}_{11}: 2$-PET], smaller changes in the PM-IRRAS spectra were observed (Fig. 1b). The characteristic vibrations of the $\mathrm{PPh}_{3}$ ligands were still clearly visible and intense, indicating that the original $\mathrm{Au}_{11}$ cluster structure did

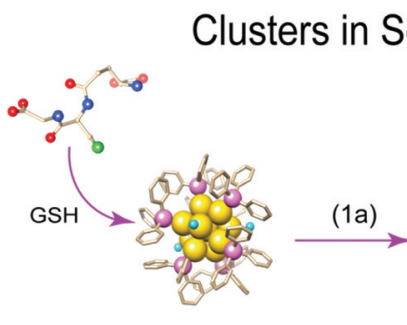

$\mathrm{Au}_{11}\left(\mathrm{PPh}_{3}\right)_{7} \mathrm{Br}_{3}$

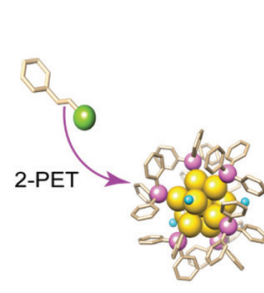

$\mathrm{Au}_{11}\left(\mathrm{PPh}_{3}\right)_{7} \mathrm{Br}_{3}$

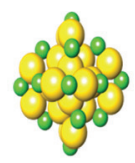

$\mathrm{Au}_{25}(\mathrm{SG})_{18}$ (1b)

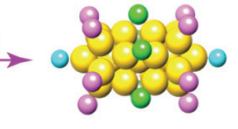

$\left[\mathrm{Au}_{25}\left(\mathrm{PPh}_{3}\right)_{10}(2-\mathrm{PET})_{5} \mathrm{Br}_{2}\right]^{2+}$

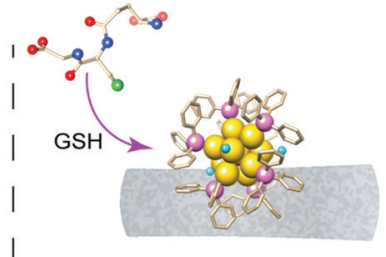

$\mathrm{Au}_{11}\left(\mathrm{PPh}_{3}\right)_{7} \mathrm{Br}_{3}$

।

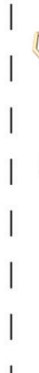

Supported Clusters

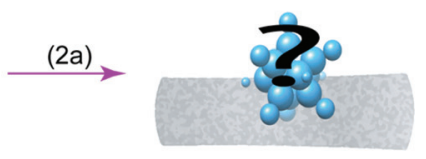

$\mathrm{Au}_{11}: \mathrm{GSH}$

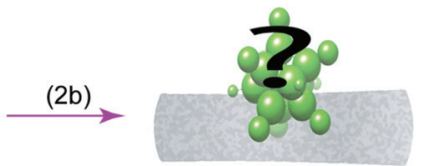

$\mathrm{Au}_{11}: 2-\mathrm{PET}$

Scheme 1 Left (1): Ligand exchange reactions of $\mathrm{Au}_{11}\left(\mathrm{PPh}_{3}\right)_{7} \mathrm{Br}_{3}$ in solution with GSH (1a) and 2-PET (1b). Right (2): Ligand exchange reactions of supported $\mathrm{Au}_{11}\left(\mathrm{PPh}_{3}\right)_{7} \mathrm{Br}_{3}$ with GSH (2a) and 2-PET (2b). Color code: $\mathrm{Au}=, \mathrm{P}=\mathrm{e}, \mathrm{S}=\mathrm{e}, \mathrm{Br}=\mathrm{O}, \mathrm{O}=\mathrm{e}$, and $\mathrm{N}=\mathbf{0}$. The organic ligand framework of the cluster structures after exchange is not shown. 
a

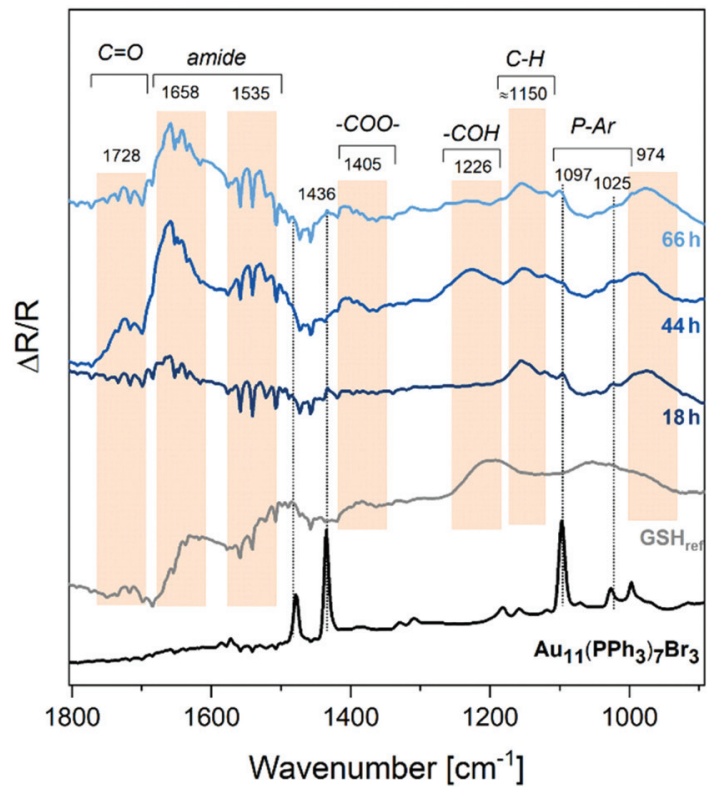

b

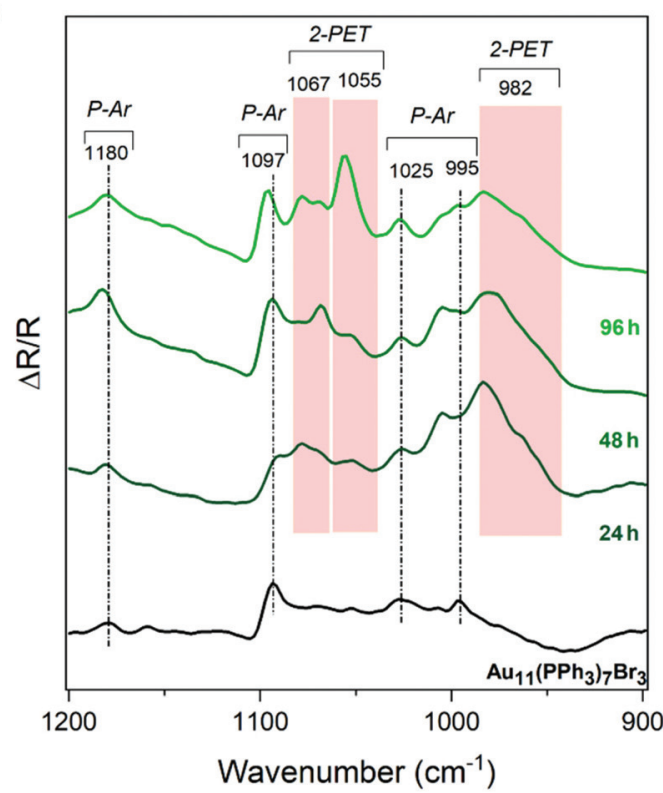

Fig. 1 PM-IRRAS spectra of the ligand exchange of supported $\mathrm{Au}_{11}\left(\mathrm{PPh}_{3}\right)_{7} \mathrm{Br}_{3}$ with GSH (a) and 2-PET (b). Bands from the initial PPh ${ }_{3}$ ligands are indicated by dashed lines, and colored areas mark regions with characteristic vibrations of the ligands. A full range $\left(1800-900 \mathrm{~cm}^{-1}\right) \mathrm{spectrum} \mathrm{of}$ the exchange with 2-PET can be found in Fig. S10. $\dagger$ A reference MIR spectrum of pure 2-PET can be found in Fig. S11. $\dagger$

not change significantly. Note that the newly incoming 2-PET shows similar infrared absorption bands to the already present $\mathrm{PPh}_{3}$ ligands. This is attributed to the characteristic aromatic ring in both structures, making it difficult to distinguish the two ligands via IR spectroscopy.

To confirm the reactivity of the supported $\mathrm{Au}_{11}\left(\mathrm{PPh}_{3}\right)_{7} \mathrm{Br}_{3}$ clusters with GSH, the ligand exchange with GSH was also monitored in situ by attenuated total reflection IR (AT-IR) spectroscopy (Fig. 2). The $\mathrm{Au}_{11}\left(\mathrm{PPh}_{3}\right)_{7} \mathrm{Br}_{3}$ clusters were dropcast directly onto a ZnSe ATR crystal instead of the aluminum plate. The crystal was mounted into an ATR flow cell, through which the GSH solution was slowly passed, while simul-
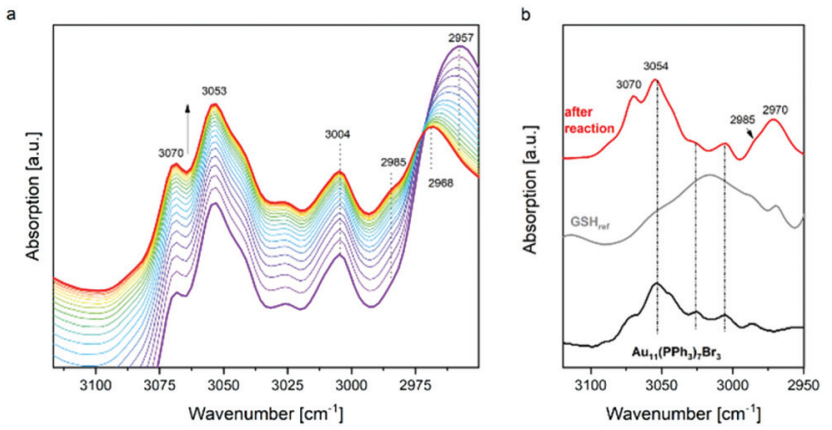

Fig. 2 (a) In situ monitoring of the $\mathrm{CH}$-stretching vibration region within the first $2 \mathrm{~h}$ of the ligand exchange between $\mathrm{Au}_{11}\left(\mathrm{PPh}_{3}\right)_{7} \mathrm{Br}_{3}$ and GSH (violet: time $0 \mathrm{~h}$, red: time $2 \mathrm{~h}$ ). Spectra have been offset for better visibility; (b): comparison of the $\mathrm{CH}$-stretching region of unreacted $\mathrm{Au}_{11}\left(\mathrm{PPh}_{3}\right)_{7} \mathrm{Br}_{3}$ dropcast, the product $\left[\mathrm{Au}_{11}: \mathrm{GSH}\right]$ after exchange and a GSH dropcast. taneously recording IR spectra (see the ESI†ं). This allowed to follow the reaction progress in shorter time intervals than with PM-IRRAS (assuming that the substrate does not affect the exchange reaction). In addition, the spectra of the dry dropcast on the ATR crystal (no solution in the cell) were recorded before and after the reaction, as well as of the pure GSH ligand.

Because of the high absorption of the solvent mixture used $\left(\mathrm{MeOH} / \mathrm{H}_{2} \mathrm{O}\right)$, only the $\mathrm{C}-\mathrm{H}$ stretching vibration region between 3100 and $2950 \mathrm{~cm}^{-1}$ is shown. Fig. 2a shows spectral changes in the first 2 hours of reaction: while the absorption features in the aromatic region $\left(>3000 \mathrm{~cm}^{-1}\right)$ were constant, indicating that the $\mathrm{PPh}_{3}$ ligands remained unchanged, a small band in the aliphatic $\mathrm{C}-\mathrm{H}$ stretching region at $\approx 2970 \mathrm{~cm}^{-1}$ characteristic of GSH was evolving. The IR absorption spectra of the unreacted $\mathrm{Au}_{11}\left(\mathrm{PPh}_{3}\right)_{7} \mathrm{Br}_{3}$ dropcast, the $\mathrm{GSH}$ reference and the product after exchange are shown in Fig. $2 \mathrm{~b}$. The presence of the intense aliphatic $\mathrm{C}-\mathrm{H}$ stretching band at $2970 \mathrm{~cm}^{-1}$ after the experiment is a clear indication that GSH reacted with the cluster dropcast, as the original $\mathrm{PPh}_{3}$ ligand does not possess any aliphatic structure motifs. After $120 \mathrm{~min}$, the absorption remained constant, indicating no further reaction.

The IR absorption of $\mathrm{Au}_{11}\left(\mathrm{PPh}_{3}\right)_{7} \mathrm{Br}_{3},\left[\mathrm{Au}_{11}\right.$ :GSH] and GSH dropcasts on the ZnSe ATR crystal was also compared at lower wavenumber regions (Fig. S12 $\dagger$ ). As in the PM-IRRAS experiments, the characteristic $\mathrm{C}=\mathrm{O}$ and amide vibrations of $\mathrm{GSH}$ can be clearly identified in the exchanged sample. The $\mathrm{PPh}_{3}$ bands were still present after exchange, as the comparison with the spectrum of $\mathrm{Au}_{11}\left(\mathrm{PPh}_{3}\right)_{7} \mathrm{Br}_{3}$ shows, again resembling the PM-IRRAS observations. In addition, no $\mathrm{S}-\mathrm{H}$ stretching 
vibration was observed around $2500 \mathrm{~cm}^{-1}$. This is a clear indication that the $\mathrm{S}$ atom of the GSH ligand present in the exchanged system $\left[\mathrm{Au}_{11}: \mathrm{GSH}\right]$ is forming a bond with either the ZnSe support material or the cluster dropcast. However, no evidence for a S-support bond could be found in the corresponding blank experiment (see Fig. S13†), confirming the existence of a preferential cluster-thiolate interaction.

To examine whether the cluster (Au core) size was altered upon ligand exchange, as reported for the reaction in solution, matrix-assisted laser desorption/ionization mass spectrometry (MALDI-MS) was conducted. Accordingly, a small amount of dropcast sample was scratched off the aluminum plate and dissolved in $\mathrm{MeOH}$ for the measurements. Interestingly, no peaks of clusters larger than $\mathrm{Au}_{11}$ were observed for both samples. This is different from ligand exchange in solution, when the cluster size increased to $\mathrm{Au}_{25}$, and is likely related to the hindered mobility of the supported clusters.

In the $\mathrm{m} / \mathrm{z}$ region between 3000 and 4400 (Fig. 3), the main fragments of $\mathrm{Au}_{11}$ clusters were found, which can be assigned to $\left[\mathrm{Au}_{11}\left(\mathrm{PPh}_{3}\right)_{x} \mathrm{Br}_{2}\right]^{+},\left[\mathrm{Au}_{10}\left(\mathrm{PPh}_{3}\right)_{x} \mathrm{Br}\right]^{+}$and $\left[\mathrm{Au}_{9}\left(\mathrm{PPh}_{3}\right)_{x}\right]^{+}$fragments, in agreement with the fragmentation pathway proposed for $\mathrm{PPh}_{3}$ protected undecagold by Tsukuda and coworkers. ${ }^{52}$ Additionally, the sample after exposure to GSH $\left[\mathrm{Au}_{11}: \mathrm{GSH}\right]$ also showed peaks indicating exchanged clusters containing $\mathrm{SG}^{-}$ instead of $\mathrm{Br}^{-}$. The fragments $\left[\mathrm{Au}_{11}\left(\mathrm{PPh}_{3}\right)_{6}(\mathrm{SG})_{2}\right]^{+}$(marked with $\left.{ }^{*}\right)$, as well as $\left[\mathrm{Au}_{10}\left(\mathrm{PPh}_{3}\right)_{7} \mathrm{SG}\right]^{+}$(marked with $\left.{ }^{* *}\right)$ and $\left[\mathrm{Au}_{10}\left(\mathrm{PPh}_{3}\right)_{6} \mathrm{SG}\right]^{+}$, could be detected. Thus, the ligand exchange of the bromide did indeed occur for glutathione. However, the most intense peaks were still associated with $\mathrm{Au}_{11}\left(\mathrm{PPh}_{3}\right)_{7} \mathrm{Br}_{3}$, indicating that only a part of the dropcast clusters did react with the GSH ligands. This may be associated with GSH solution having less access to clusters close to the support surface. However, for the MALDI-MS analysis it was necessary to scratch off some clusters from the plate and dissolve them for the measurements. Thereby, not only the upper layers of the dropcast that had better access to the GSH ligands and reacted, but the whole sample thickness was probed, explain-

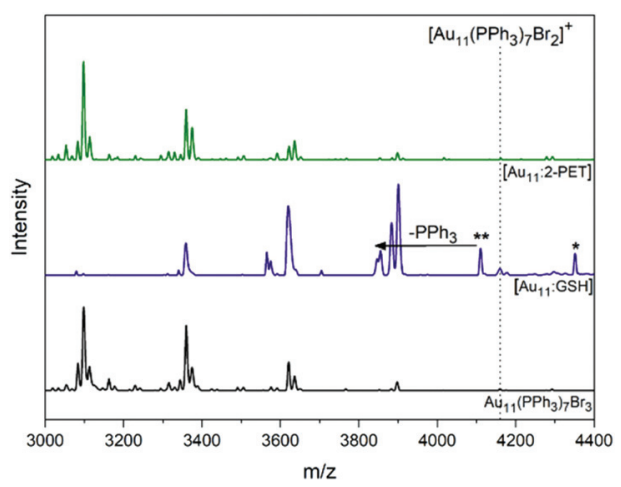

Fig. 3 MALDI-MS spectra of $\mathrm{Au}_{11}\left(\mathrm{PPh}_{3}\right)_{7} \mathrm{Br}_{3}$ before and after the ligand exchange reaction $\left[\mathrm{Au}_{11}: \mathrm{GSH}\right]$ and $\left[\mathrm{Au}_{11}: 2-\mathrm{PET}\right]$. Fragments of $\left[\mathrm{Au}_{11}: \mathrm{GSH}\right]$ confirming ligand exchange with GSH are marked with asterisks: * for $\left[\mathrm{Au}_{11}\left(\mathrm{PPh}_{3}\right)_{6}(\mathrm{SG})_{2}\right]^{+}$and $* *$ for $\left[\mathrm{Au}_{10}\left(\mathrm{PPh}_{3}\right)_{7} \mathrm{SG}\right]^{+}$(further fragmentation to $\left[\mathrm{Au}_{10}\left(\mathrm{PPh}_{3}\right)_{6} \mathrm{SG}\right]^{+}$indicated by the arrow). ing the high percentage of unreacted $\mathrm{Au}_{11}\left(\mathrm{PPh}_{3}\right)_{7} \mathrm{Br}_{3}$ peaks in the spectrum.

The MALDI-MS of $\left[\mathrm{Au}_{11}: 2\right.$-PET] between $\mathrm{m} / \mathrm{z} 3000$ and 4400 resembled the one of $\mathrm{Au}_{11}\left(\mathrm{PPh}_{3}\right)_{7} \mathrm{Br}_{3}$, indicating that no exchanged $\mathrm{Au}_{11}$ clusters were present. Additionally, several peaks below $\mathrm{m} / \mathrm{z} 2000$, associated with smaller gold components, were detected (Fig. S6 $\dagger$ ). This suggests, together with the LA-ICP-MS results (as shown below), that the $\mathrm{Au}_{11}$ cluster dropcast reacted with 2-PET to smaller Au components, resulting in a polydisperse mixture. For $\left[\mathrm{Au}_{11}: \mathrm{GSH}\right]$, only a few signals at low mass (below $m / z$ 3000) were detected by MALDI-MS, indicating the stability of the cluster core structure.

Complementing IR spectroscopy and MALDI-MS, elemental analysis was performed with laser ablation inductively coupled plasma mass spectrometry (LA-ICP-MS), confirming the presence of sulfur, phosphorus and gold in the reacted samples. After the reaction, the aluminum plates with the supported cluster (samples $\left[\mathrm{Au}_{11}: \mathrm{GSH}\right]$ and $\left[\mathrm{Au}_{11}: 2\right.$-PET]) were immediately placed in the sample compartment of the instrument (without the need to remove and dissolve part of the cluster dropcast), thus allowing direct investigation of the entire cluster-on-support system. As can be seen in Fig. 4 by the significant rise of the $\mathrm{S} / \mathrm{Au}$ ratio, sulfur was found in both exchanged samples $\left[\mathrm{Au}_{11}: \mathrm{GSH}\right]$ and $\left[\mathrm{Au}_{11}: 2\right.$-PET]. Differences were noticed among the thiols, with more sulfur being present after the exposure of $\mathrm{Au}_{11}$ clusters to the water-soluble ligand GSH.

When comparing the $\mathrm{P} / \mathrm{Au}$ ratios in Fig. 4, no significant change occurred upon the reaction of $\mathrm{Au}_{11}\left(\mathrm{PPh}_{3}\right)_{7} \mathrm{Br}_{3}$ with the thiol ligands. This is consistent with the observations by IR spectroscopy, in which triphenylphosphine was still detected in the samples after the reaction. One can therefore assume that the halide ligands of $\mathrm{Au}_{11}\left(\mathrm{PPh}_{3}\right)_{7} \mathrm{Br}_{3}$ are exchanged by thiolates. On preserving the $\mathrm{Au}_{11}$ cluster size, complete exchange would result in the formation of $\mathrm{Au}_{11}\left(\mathrm{PPh}_{3}\right)_{7}(\mathrm{SR})_{3}$. Clusters of that principal formula have already been synthesized, ${ }^{53,54}$ but, to our knowledge, never by ligand exchange from $\mathrm{Au}_{11}\left(\mathrm{PPh}_{3}\right)_{7} \mathrm{Br}_{3}$. Indeed, fragments corres-

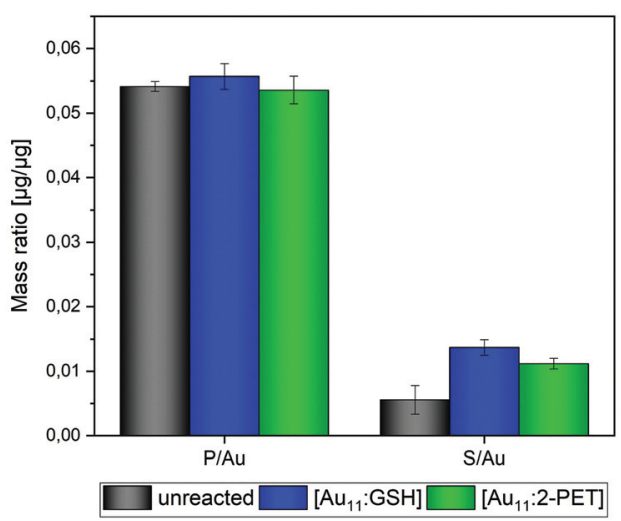

Fig. 4 Mass ratios $\mathrm{P} / \mathrm{Au}$ and $\mathrm{S} / \mathrm{Au}$ for unreacted clusters $\mathrm{Au}_{11}\left(\mathrm{PPh}_{3}\right)_{7} \mathrm{Br}_{3}$

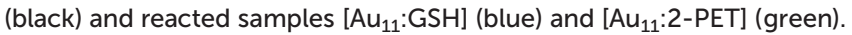


ponding to that principal formula have been observed for $\left[\mathrm{Au}_{11}: \mathrm{GSH}\right]$ by MALDI-MS (see Fig. 3 ).

However, for the sample $\left[\mathrm{Au}_{11}: 2\right.$-PET] reacted with 2-PET, no such clusters could be identified in MALDI-MS, even though the sulfur content in the sample increased upon reaction (Fig. 4, right). Furthermore, taking into account the presence of smaller cluster species detected by MALDI-MS (Fig. S6 $\dagger$ ), this strongly suggested etching of the $\mathrm{Au}_{11}$ clusters by 2-PET. In addition, a slight yellowish color of the solution (previously colorless) was noted after the reaction with 2-PET, which indicated that the gold was partially dissolved in the ligand solution. To prove this hypothesis, the solution before and after the reaction was dropcast and the remaining residues were measured by LA-ICP-MS. The increase in the intensity of the ${ }^{197} \mathrm{Au}$ and ${ }^{31} \mathrm{P}$ signals in the reacted solution (Fig. S8 $\dagger$ ) indeed confirmed partial leaching of gold compounds. However, at this point, it is unclear how the etching and dissolution exactly progressed.

Furthermore, it was demonstrated that the thiol exchange ligands only interacted with the supported clusters, but not with the alumina support. The LA-ICP-MS line scans in Fig. 5 show that the $\mathrm{S}$ signal in the exchanged samples $\left[\mathrm{Au}_{11}: \mathrm{GSH}\right]$ and $\left[\mathrm{Au}_{11}: 2\right.$-PET] was much higher at positions where clusters were deposited, corroborated by the simultaneous enhancement of the Au signal (beige regions in Fig. 5). If the laser was instead directed to positions on the support plate without clusters, the S signal remained at the background level (grey regions in Fig. 5). This, together with blank experiments (see Fig. $\mathrm{S} 7 \dagger$ ), confirmed a selective $\mathrm{Au}-\mathrm{S}$ interaction and excluded random adsorption of thiolates on the surface of the support material.

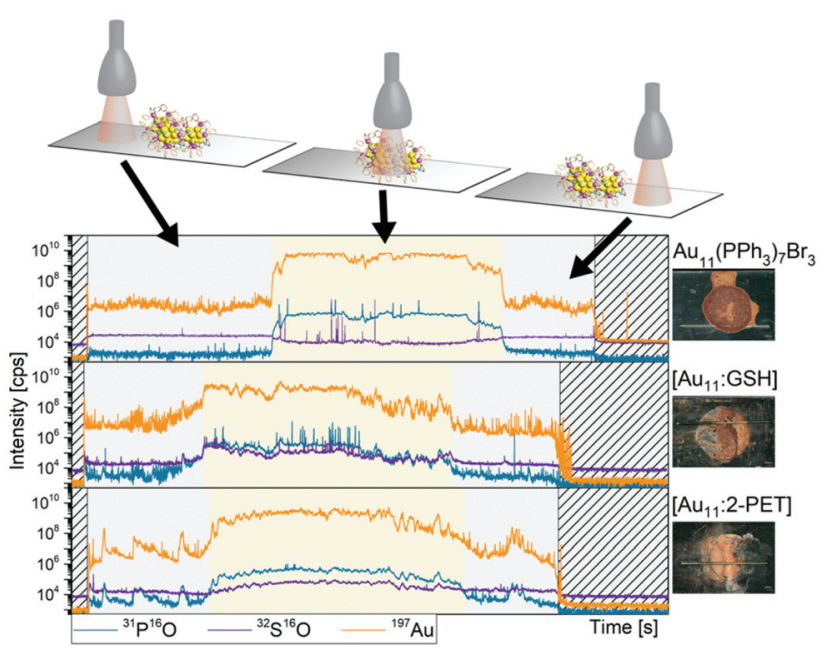

Fig. 5 LA-ICP-MS line scans of $\mathrm{Au}_{11}\left(\mathrm{PPh}_{3}\right)_{7} \mathrm{Br}_{3}$ (top), product [ $\mathrm{Au}_{11}: \mathrm{GSH}$ ] after exchange with $\mathrm{GSH}$ (middle) and product [ $\left.\mathrm{Au}_{11}: 2-\mathrm{PET}\right]$ after exchange with 2-PET (bottom). Background colors in profiles: laser-off (grey hatched), laser-on but not directed onto cluster dropcast (grey), laser on and directed onto cluster dropcast (beige). The optical microscopy images of the samples after LA-ICP-MS analysis on the right show the line scan of the laser across the plates.

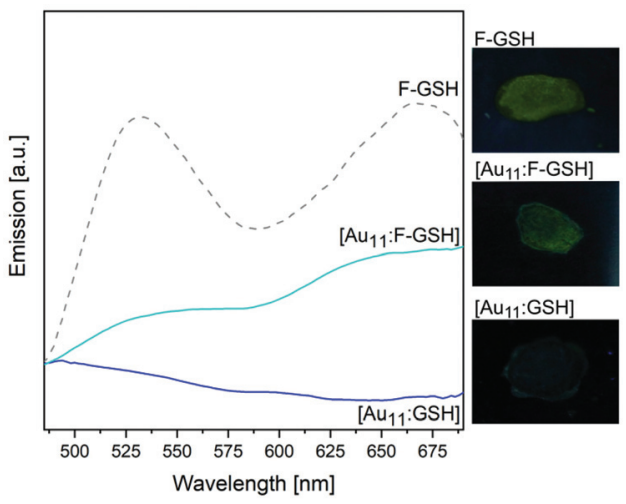

Fig. 6 Photoluminescence spectra of dropcast F-GSH and the samples after reaction with glutathionates, $\left[\mathrm{Au}_{11}: \mathrm{F}-\mathrm{GSH}\right]$ and $\left[\mathrm{Au}_{11}: \mathrm{GSH}\right]$ with excitation at $450 \mathrm{~nm}$. The images on the right show the fluorescence behaviour of the solid samples on the support plate upon irradiation with UV/Vis light.

To further test the ligand exchange behavior of supported $\mathrm{Au}_{11}$ clusters with glutathionates and to expand the scope of this new modification pathway, the reaction was also repeated with fluorescein labeled L-glutathione (F-GSH). Since fluorescent Au nanoclusters are increasingly studied for a range of applications, ${ }^{40,55}$ modifying their ligand sphere in the solid state might become of great importance. The reaction conditions were identical to the ones of the exchange with regular L-glutathione. Therefore, the outcome expected was partial replacement of the original ligands of $\mathrm{Au}_{11}\left(\mathrm{PPh}_{3}\right)_{7} \mathrm{Br}_{3}$ with F-GSH. As this newly incoming ligand is strongly fluorescent, this should result in the supported cluster system becoming photoluminescent. As can be seen in Fig S18, $\uparrow$ the unreacted $\mathrm{Au}_{11}$ clusters as well as the product of the exchange with regular glutathione, $\left[\mathrm{Au}_{11}: \mathrm{GSH}\right]$, did not exhibit any relevant fluorescence pattern. Fluorescence activity should therefore be a clear indication of a change in the system induced by the fluorescein labeled exchange thiol.

The photoluminescence spectra of the glutathione-reacted systems, $\left[\mathrm{Au}_{11}: \mathrm{GSH}\right]$ and $\left[\mathrm{Au}_{11}: \mathrm{F}-\mathrm{GSH}\right]$, are shown in Fig. 6. Fluorescence activity was indeed induced in the sample after exchange with F-GSH. The bands appearing are broad, but still resemble the ones of the solid F-GSH ligand supported on the same aluminum plate as used for the reactions. In addition, the fluorescent behavior can also be observed visually upon exposing the sample plates to UV light, as shown by the photographs in Fig. 6.

\section{Conclusions}

This work presents the first proof of the partial functionalization of immobilized nanoclusters on surfaces by ligand exchange. The reaction of $\mathrm{Au}_{11}\left(\mathrm{PPh}_{3}\right)_{7} \mathrm{Br}_{3}$ on an alumina surface with two different thiol ligands, GSH and 2-PET, was investigated by combining IR spectroscopy (PM-IRRAS, ATR-IR) with mass spectrometry (LA-ICP-MS, MALDI-MS). The presence 
of the exchange ligands in the reacted samples was confirmed by infrared measurements, while LA-ICP-MS indicated a selective $\mathrm{Au}-\mathrm{S}$ interaction as the incoming thiolates only interacted with the cluster itself, but not with the alumina support. Whereas ligand exchange in solution is accompanied by core growth from $\mathrm{Au}_{11}$ to $\mathrm{Au}_{25}$, the core size of the supported $\mathrm{Au}_{11}$ clusters did not increase. Moreover, after exchange, the resulting clusters exhibited a mixed ligand shell, containing both the initial phosphine ligand $\mathrm{PPh}_{3}$, as well as the incoming thiolate. Tremendous differences were found depending on the chemical nature of the thiolate: the water-soluble GSH led to clusters whose core size was maintained as $\mathrm{Au}_{11}$, with part of the halide ligands exchanging with glutathione. However, when 2-PET was used as the exchange ligand, the cluster size decreased and smaller $\mathrm{Au}$ components were formed, accompanied by the partial leaching of $\mathrm{Au}$ compounds into the solution.

This novel functionalization route towards obtaining atomically controlled surfaces enables further insights into clustersurface interactions, which is key to applications in several fields. The current study is just a starting point for the future optimization of such systems. Whenever applications require to induce specific properties (fluorescence, chirality, solubility, etc.), tailored cluster/ligand/surface systems must be explored in more detail. As a first step in this direction, we could show that fluorescence can be induced in the supported cluster systems by reacting immobilized $\mathrm{Au}_{11}$ clusters with fluorescein labeled glutathione.

\section{Conflicts of interest}

There are no conflicts to declare.

\section{Acknowledgements}

GR acknowledges financial support from the Austrian Science Fund (FWF) via grants ComCat (I1041-N28) and DK+ Solids4Fun (W1243). VT thanks Prof. T. Bürgi's research group for help during her stay at the University of Geneva. The authors thank Dr. André Vogel for his valuable input concerning the synthesis of fluorescent glutathione derivatives.

\section{References}

1 R. Jin, Nanoscale, 2010, 2, 343-362.

2 R. R. Nasaruddin, T. Chen, N. Yan and J. Xie, Coord. Chem. Rev., 2018, 368, 60-79.

3 W. Kurashige, Y. Niihori, S. Sharma and Y. Negishi, Coord. Chem. Rev., 2016, 320-321, 238-250.

4 R. C. Jin, C. J. Zeng, M. Zhou and Y. X. Chen, Chem. Rev., 2016, 116, 10346-10413.

5 S. Takano and T. Tsukuda, in Frontiers of Nanoscience, ed. T. Tsukuda and H. Häkkinen, Elsevier, 2015, vol. 9, pp. 9-38.
6 K. Konishi, in Gold Clusters, Colloids and Nanoparticles I. Structure and Bonding, ed. D. M. P. Mingos, Springer, Cham, 2014, vol. 161, pp. 49-86.

7 Y. Negishi, Y. Niihori and W. Kurashige, in Frontiers of Nanoscience, ed. T. Tsukuda and H. Häkkinen, Elsevier, 2015, vol. 9, pp. 39-71.

8 X. Kang, Y. Song, H. Deng, J. Zhang, B. Liu, C. Pan and M. Zhu, RSC Adv., 2015, 5, 66879-66885.

9 S. Hossain, W. Kurashige, S. Wakayama, B. Kumar, L. V. Nair, Y. Niihori and Y. Negishi, J. Phys. Chem. C, 2016, 120, 25861-25869.

10 M. J. Cowan, T. Higaki, R. Jin and G. Mpourmpakis, J. Phys. Chem. C, 2019, 123, 20006-20012.

11 M. G. Warner, S. M. Reed and J. E. Hutchison, Chem. Mater., 2000, 12, 3316-3320.

12 Y. Niihori, S. Hossain, S. Sharma, B. Kumar, W. Kurashige and Y. Negishi, Chem. Rec., 2017, 17, 473-484.

13 G. Li, H. Abroshan, C. Liu, S. Zhuo, Z. Li, Y. Xie, H. J. Kim, N. L. Rosi and R. Jin, ACS Nano, 2016, 10, 7998-8005.

14 R. Guo and R. W. Murray, J. Am. Chem. Soc., 2005, 127, 12140-12143.

15 J. Liu, K. S. Krishna, Y. B. Losovyj, S. Chattopadhyay, N. Lozova, J. T. Miller, J. J. Spivey and C. S. S. R. Kumar, Chem. - Eur. J., 2013, 19, 10201.

16 Y. Niihori, S. Hossain, B. Kumar, L. V. Nair, W. Kurashige and Y. Negishi, APL Mater., 2017, 5, 053201.

17 C. L. Heinecke, T. W. Ni, S. Malola, V. Mäkinen, O. A. Wong, H. Häkkinen and C. J. Ackerson, J. Am. Chem. Soc., 2012, 134, 13316-13322.

18 N. Goswami, J. Li and J. Xie, in Frontiers of Nanoscience, ed. T. Tsukuda and H. Häkkinen, Elsevier, 2015, vol. 9, pp. 297-345.

19 G. Pramanik, J. Humpolickova, J. Valenta, P. Kundu, S. Bals, P. Bour, M. Dracinsky and P. Cigler, Nanoscale, 2018, 10, 3792-3798.

20 H.-H. Deng, X.-Q. Shi, F.-F. Wang, H.-P. Peng, A.-L. Liu, X.-H. Xia and W. Chen, Chem. Mater., 2017, 29, 1362-1369.

21 A. Sels, G. Salassa, S. Pollitt, C. Guglieri, G. Rupprechter, N. Barrabés and T. Bürgi, J. Phys. Chem. C, 2017, 121, 10919-10926.

22 S. Knoppe, A. C. Dharmaratne, E. Schreiner, A. Dass and T. Bürgi, J. Am. Chem. Soc., 2010, 132, 16783-16789.

23 S. Takano and T. Tsukuda, J. Phys. Chem. Lett., 2016, 7, 4509.

24 M. J. Hostetler, A. C. Templeton and R. W. Murray, Langmuir, 1999, 15, 3782-3789.

25 Y. Song and R. W. Murray, J. Am. Chem. Soc., 2002, 124, 7096-7102.

26 Y. Song, T. Huang and R. W. Murray, J. Am. Chem. Soc., 2003, 125, 11694-11701.

27 R. L. Donkers, Y. Song and R. W. Murray, Langmuir, 2004, 20, 4703-4707.

28 R. Guo, Y. Song, G. Wang and R. W. Murray, J. Am. Chem. Soc., 2005, 127, 2752-2757.

29 A. Fernando and C. M. Aikens, J. Phys. Chem. C, 2015, 119, 20179-20187. 
30 G. H. Woehrle, M. G. Warner and J. E. Hutchison, J. Phys. Chem. B, 2002, 106, 9979-9981.

31 G. H. Woehrle and J. E. Hutchison, Inorg. Chem., 2005, 44, 6149-6158.

32 G. H. Woehrle, L. O. Brown and J. E. Hutchison, J. Am. Chem. Soc., 2005, 127, 2172-2183.

33 L. C. McKenzie, T. O. Zaikova and J. E. Hutchison, J. Am. Chem. Soc., 2014, 136, 13426-13435.

34 L. Wang, J. Peng, Z. Tang, X. Kang, M. Fu and S. Chen, Appl. Catal., A, 2018, 557, 1-6.

35 C. Liu, H. Abroshan, C. Yan, G. Li and M. Haruta, ACS Catal., 2016, 6, 92-99.

36 K. Zheng, J. Zhang, D. Zhao, Y. Yang, Z. Li and G. Li, Nano Res., 2019, 12, 501-507.

37 Y. Wang, X.-K. Wan, L. Ren, H. Su, G. Li, S. Malola, S. Lin, Z. Tang, H. Häkkinen, B. K. Teo, Q.-M. Wang and N. Zheng, J. Am. Chem. Soc., 2016, 138, 3278.

38 Y. Liu, H. Tsunoyama, T. Akita and T. Tsukuda, J. Phys. Chem. C, 2009, 113, 13457-13461.

39 Y. Negishi, Y. Matsuura, R. Tomizawa, W. Kurashige, Y. Niihori, T. Takayama, A. Iwase and A. Kudo, J. Phys. Chem. C, 2015, 119, 11224-11232.

40 L.-Y. Chen, C.-W. Wang, Z. Yuan and H.-T. Chang, Anal. Chem., 2015, 87, 216-229.

41 Z. Wu, D.-E. Jiang, A. K. P. Mann, D. R. Mullins, Z.-A. Qiao, L. F. Allard, C. Zeng, R. Jin and S. H. Overbury, J. Am. Chem. Soc., 2014, 136, 6111-6122.

42 G. Li and R. Jin, J. Am. Chem. Soc., 2014, 136, 11347-11354.
43 Y. Shichibu, Y. Negishi, T. Tsukuda and T. Teranishi, J. Am. Chem. Soc., 2005, 127, 13464-13465.

44 A. Das, T. Li, K. Nobusada, Q. Zeng, N. L. Rosi and R. Jin, J. Am. Chem. Soc., 2012, 134, 20286-20289.

45 Y. Shichibu, Y. Negishi, T. Watanabe, N. K. Chaki, H. Kawaguchi and T. Tsukuda, J. Phys. Chem. C, 2007, 111, 7845-7847.

46 Z. Wu and R. Jin, Chem. - Eur. J., 2013, 19, 12259-12263.

47 W. W. Weare, S. M. Reed, M. G. Warner and J. E. Hutchison, J. Am. Chem. Soc., 2000, 122, 12890-12891.

48 L. M. Landino, C. M. Brown, C. A. Edson, L. J. Gilbert, N. Grega-Larson, A. J. Wirth and K. C. Lane, Anal. Biochem., 2010, 402, 102-104.

49 G. Rupprechter and C. Weilach, J. Phys.: Condens. Matter, 2008, 20, 184019.

50 M. Bieri and T. Bürgi, Langmuir, 2005, 21, 1354-1363.

51 W. Qian and S. Krimm, Biopolymers, 1994, 34, 1377-1394.

52 R. Tomihara, K. Hirata, H. Yamamoto, S. Takano, K. Koyasu and T. Tsukuda, ACS Omega, 2018, 3, 62376242.

53 K. Nunokawa, S. Onaka, M. Ito, M. Horibe, T. Yonezawa, H. Nishihara, T. Ozeki, H. Chiba, S. Watase and M. Nakamoto, J. Organomet. Chem., 2006, 691, 638-642.

54 S. Takano, S. Yamazoe and T. Tsukuda, APL Mater., 2017, 5, 053402 .

55 J. Yang, F. Wang, H. Yuan, L. Zhang, Y. Jiang, X. Zhang, C. Liu, L. Chai, H. Li and M. Stenzel, Nanoscale, 2019, 11, 17967-17980. 